JOÃO MARCELO BRANDINI NÉSPOLI

Situação epidemiológica da tuberculose bovina no Estado de Mato Grosso

São Paulo

2012 


\title{
Situação epidemiológica da tuberculose bovina no Estado de Mato Grosso
}

\begin{abstract}
Dissertação apresentada ao Programa de Pósgraduação em Epidemiologia Experimental Aplicada às Zoonoses da Faculdade de Medicina Veterinária e Zootecnia da Universidade de São Paulo para obtenção do título de Mestre em Ciências
\end{abstract}

\section{Departamento:}

Medicina Veterinária Preventiva e Saúde Animal

Área de concentração:

Epidemiologia Experimental Aplicada às Zoonoses

Orientador:

Prof. Dr. José Soares Ferreira Neto 
Autorizo a reprodução parcial ou total desta obra, para fins acadêmicos, desde que citada a fonte.

DADOS INTERNACIONAIS DE CATALOGAÇÃO-NA-PUBLICAÇÃO

(Biblioteca Virginie Buff D’Ápice da Faculdade de Medicina Veterinária e Zootecnia da Universidade de São Paulo)

Néspoli, João Marcelo Brandini

Situação epidemiológica da tuberculose bovina no Estado de Mato Grosso / João Marcelo Brandini Néspoli. -- 2012.

$44 \mathrm{f}$.

Dissertação (Mestrado) - Universidade de São Paulo. Faculdade de Medicina Veterinária e Zootecnia. Departamento de Medicina Veterinária Preventiva e Saúde Animal, São Paulo, 2012

Programa de Pós-Graduação: Epidemiologia Experimental Aplicada às Zoonoses. Área de concentração: Epidemiologia Experimental Aplicada às Zoonoses.

Orientador: Prof. Dr. José Soares Ferreira Neto.

1. Brasil. 2. Mato Grosso. 3. Prevalência. 4. Fatores de risco. 5. Fatores associados. 6. Bovina. 7. Tuberculose. I. Título. 


\section{INIVLRSIDADF DF SÃO PAULO \\ Faculdade de Medicina Veterinaria e Zootecnia \\ (idide l niversitária "Armando de Salles Olis cirn" Comissão Bioética \\ CERTIFICADO}

Certificamos que o Projeto intitulado "Epidemiologia e controle da brucelose e tuberculose bovinas no Brasil: bases para as intervenções", protocolo $n^{\circ} 441 / 2004$, utilizando 180 hamsters, sob a responsabilidade do Prof. Dr. José Soares Ferreira Neto, está de acordo com os princípios éticos de experimentação animal da Comissão de Bioética da Faculdade de Medicina Veterinária e Zootecnia da Universidade de São Paulo e foi aprovado pela referida Comissão em sessão de 14/04/04.

(We certify that the Research "Epidemiology and contrl of the bovine brucellosis and huberculosis in Brazil: basis for the interventions" protocol number 441/2004, utilizing 180 hamsters, under the responsibility of Prof Dr. José Soares Ferreira Neto, agree with Ethical Principles in Animal Research adopted by Bioethic Commission of the Faculty of Veterinary Medicine and Zootechny of University of São Paulo and was approved in 04/14/2004 meeting.

São Paulo, 16 de abril de 2004

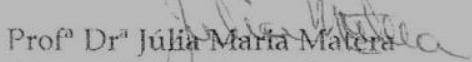
Presidente da Comissão de Bioética FMVZ/USP 


\section{FOLHA DE AVALIAÇÃO}

Nome: NÉSPOLI, João Marcelo Brandini

Título: Situação epidemiológica da tuberculose bovina no Estado de Mato Grosso

Dissertação apresentada ao Programa de PósGraduação em Epidemiologia Experimental Aplicada às Zoonoses da Faculdade de Medicina Veterinária e Zootecnia da Universidade de São Paulo para obtenção do título de Mestre em Ciências

Data: $24,4,2012$

\section{Banca examinadora}

- Prof. Dr. Sor foren Fe Neto

Instituição: FMVt- Iff Julgamento:

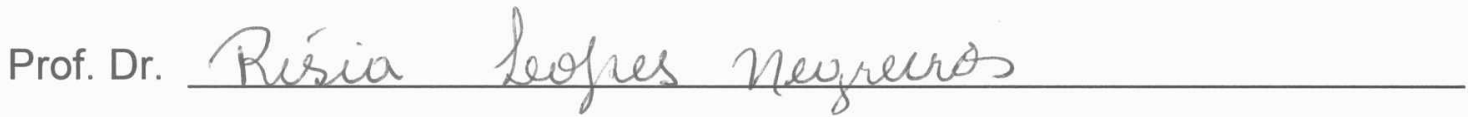

Instituição: INDEA/MT Julgamento: Afrocrado

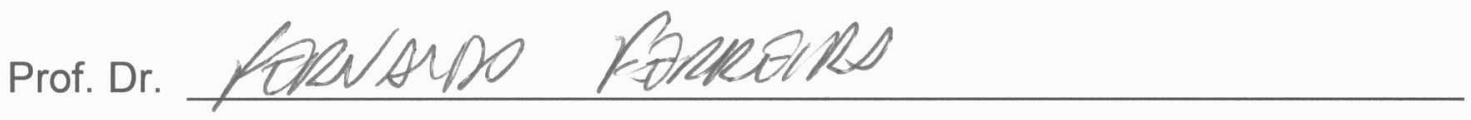

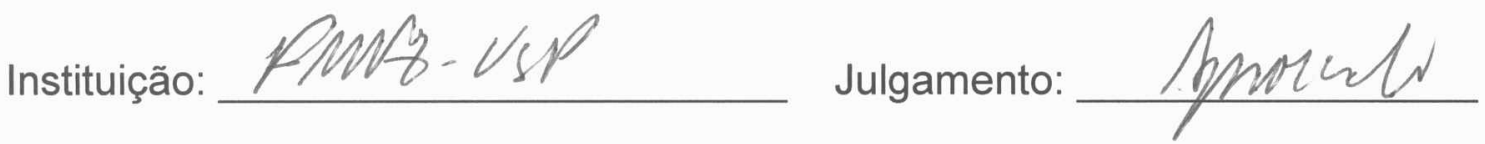


DEDICATÓRIAS

Aos meus pais,

filhas e amada esposa. 


\section{AGRADECIMENTOS}

Ao Prof. Dr. José Soares Ferreira Neto, pela orientação, vastos conhecimentos e simplicidade para ensiná-los;

A minha esposa, Jeusa Nascimento Azevedo Néspoli, por ter me auxiliado com o texto, e juntamente com meus pais, possibilitado meu afastamento para realização deste trabalho;

À grande parceira de trabalho e amiga, Janice Elena loris Barddal, pela inabalável luta em favor do PNCEBT no Estado de Mato Grosso;

Ao Instituto de Defesa Agropecuária do Estado de Mato Grosso (INDEA/MT), nas pessoas dos colegas que em mim depositaram sua confiança: Roberto Renato Pinheiro da Silva (Coordenador), Maria Auxiliadora da Rocha Pereira Diniz (Diretora) e Décio Coutinho (Presidente);

Ao Ministério da Agricultura Pecuária e Abastecimento, nas pessoas de: Ênio José de Arruda Martins (Chefe do SEDESA/ MT), Alzira Menezes de Araújo Catunda (Chefe da Divisão Técnica), Francisco Moraes Chico Costa (Superintendente/ MT) e José Ricardo Lobo (Gerente Nacional do PNCEBT);

Ao Prof. Dr. Fernando Ferreira, pelo programa informatizado para inclusão dos questionários e auxílio na análise do banco de dados;

Ao meu irmão, Prof. Dr. Pedro Eduardo Brandini Néspoli, por ministrar o treinamento prático aos médicos veterinários envolvidos na pesquisa; 
Aos amigos da Coordenadoria de Controle das Doenças dos Animais (CCDA), especialmente à Dr. ${ }^{a}$ Rísia Lopes Negreiros, que me apontou o caminho e encorajou.

A todos os colegas do INDEA/ MT que executaram as atividades de campo.

Aos colegas da Comissão de Qualificação do INDEA/ MT, Valtuil, Maria Justina e Jussara.

Aos colegas do Laboratório de Epidemiologia da FMVZ/ USP, especialmente à Bianca, Guilherme e Zé, pelo apoio e amizade. 


\section{RESUMO}

NÉSPOLI, J. M. B. Situação epidemiológica da tuberculose bovina no Estado de Mato Grosso. [Epidemiological situation of bovine tuberculosis in the State of Mato Grosso]. 2012. 44 f. Dissertação (Mestrado em Ciências) - Faculdade de Medicina Veterinária e Zootecnia, Universidade de São Paulo, São Paulo, 2012.

Realizou-se um estudo para caracterizar a situação epidemiológica da tuberculose bovina no Estado de Mato Grosso. O Estado foi estratificado em quatro circuitos produtores. Em cada circuito as propriedades foram sorteadas aleatoriamente e, dentro dessas, escolheu-se de forma aleatória um número pré-estabelecido de animais, os quais foram submetidos ao teste tuberculínico Cervical Comparativo. No total foram amostrados 28.878 animais, provenientes de 1.133 propriedades. Os animais que resultaram inconclusivos foram retestados com o mesmo procedimento diagnóstico em intervalo mínimo de 60 dias. Foram classificadas como foco de tuberculose as propriedades com até 20 bovinos amostrados e pelo menos um resultado positivo, assim como, aquelas com 40 animais amostrados e dois ou mais resultados positivos. Em cada propriedade amostrada aplicou-se um questionário para verificar o tipo de exploração e as práticas de criação e sanitárias que poderiam constituir fatores de risco para a doença. As prevalências de focos e de animais infectados no Estado foram de $1,3 \%[0,7 ; 2,4 \%]$ e $0,123 \%[0,034 ; 0,440 \%]$, respectivamente. Para os circuitos as prevalências de focos e de animais infectados foram, respectivamente, de: circuito pantanal, $0,0[0,0 ; 2,0]$ e $0,000[0,000 ; 0,076]$; circuito leite, $1,3[0,5 ; 3,1]$ e $0,037[0,008 ; 0,168]$; circuito engorda, $0,7[0,2 ; 2,7]$ e 
$0,010[0,003 ; 0,043]$; circuito cria, $1,7[0,7 ; 4,1]$ e $0,240[0,064 ; 0,904]$. O pequeno número de casos detectados (12) inviabilizou um estudo completo para individualização dos fatores de risco envolvidos. Resultaram associados à condição de foco os tipos de exploração leite e misto $\left(\chi^{2}=11,8 ; p=0,003\right)$, entrega de leite $\left(\chi^{2}=7,8 ; p=0,006\right)$ e ordenha mecanizada $\left(\chi^{2}=9,1 ; p=0,006\right)$. No Estado a prevalência de tuberculose bovina, tanto de focos quanto de animais, é baixa e a infecção está mais concentrada em propriedades de leite com maior grau de tecnificação no modo de produção. Em vista disso, a implementação de um sistema de vigilância para detecção e saneamento dos focos residuais constitui a melhor alternativa para o controle da doença no Estado.

Palavras chave: Brasil. Mato Grosso. Prevalência. Fatores de risco. Fatores associados. Bovina. Tuberculose. 


\section{ABSTRACT}

\section{NÉSPOLI, J. M. B. Epidemiological situation of bovine tuberculosis in the State}

of Mato Grosso. [Situação epidemiológica da tuberculose bovina no Estado de Mato Grosso]. 2012. 44 f. Dissertação (Mestrado em Ciências) - Faculdade de Medicina Veterinária e Zootecnia, Universidade de São Paulo, São Paulo, 2012.

A study to characterize the epidemiological situation of bovine tuberculosis in the State of Mato Grosso was conducted. The State was divided into four regions of production. The properties were randomly drawn for each of the regions and, among those a pre-established number of animals was selected, also in a random fashion, which were subjected to the Comparative Cervical tuberculin test. A total of 28,878 animals from 1,133 farms were sampled. Animals with inconclusive results were "retested using the same diagnostic procedure with a minimum interval of 60 days. Herds were classified as tuberculosis infected when there was at least one positive result in up to 20 bovines tested as well as two or more positive results in 40 animals tested. A survey was completed for each property sampled to determine the type of farming, husbandry and sanitary practices, which could be risk factors for the disease. The prevalence of infected herds and animals in the State were, respectively: $1.3 \%[0.7 ; 2.4 \%]$ and $0.123 \%[0.034 ; 0.440 \%]$. For each region, the prevalence of infected herds and animals were: pantanal region, $0.0[0.0 ; 2.0]$ and 0.000 [0.000; 0.076]; dairy region, 1.3 [0.5; 3.1] and 0.037 [0.008; 0.168]; fattening cattle region, 0.7 [0.2; 2.7] and 0.010 [0.003; 0.043]; calf rearing region, 1.7 [0.7; 4.1] and $0.240[0.064 ; 0.904]$. The small number of cases detected (12) prevented a 
complete study to individualize the risk factors involved. What resulted to be associated with positive herds were: dairy and mixed type of farming $\left(\chi^{2}=11.8 ; p=\right.$ $0.003)$, milk delivery $\left(\chi^{2}=7.8 ; p=0.006\right)$ and mechanical milking $\left(\chi^{2}=9.1 ; p=0.006\right)$. The prevalence of bovine tuberculosis in the State of Mato Grosso is low for both infected herds and animals and the infection is concentrated in dairy farms with higher technology farming practices. In sight of this, the implementation of a surveillance system for detection and sanitation of residual outbreaks are the best alternative for the control of the disease in the state.

Key words: Brazil. Mato Grosso. Prevalence. Risk factors. Associated factors. Bovine. Tuberculosis. 


\section{LISTA DE ILUSTRAÇÕES}

Figura 1 - Mapa do Estado de Mato Grosso com a divisão dos circuitos produtores: pantanal (1), leite (2), engorda (3) e cria (4). No detalhe a localização do Estado no Brasil - São Paulo -2011 


\section{LISTA DE TABELAS}

Tabela 1 - Resumo censitário do efetivo bovino e detalhes da amostra estudada, segundo os circuitos produtores- Mato Grosso - 2011

Tabela 2 - Prevalência de focos de tuberculose bovina e respectivo intervalo de confiança (IC) por circuito produtor e para o Estado - Mato Grosso 2011 26

Tabela 3 - Prevalência de focos de tuberculose bovina estratificada por tipo de exploração nos circuitos produtores - Mato Grosso - 2011 26

Tabela 4 - Prevalência de bovinos fêmeas e machos reprodutores com idade $\geq 24$ meses positivos para tuberculose e respectivo intervalo de confiança (IC) por circuito produtor e para o Estado - Mato Grosso - 2011 ................ 26

Tabela 5 - Resultados da análise univariada dos possíveis fatores de risco para tuberculose bovina que resultaram em $p \leq 0,20$ - Mato Grosso - 2011 ... 27 
LISTA DE ABREVIATURAS E SIGLAS

$\begin{array}{ll}\text { FMVZ } & \text { Faculdade de Medicina Veterinária e Zootecnia } \\ \text { INDEA/ MT } & \text { Instituto de Defesa Agropecuária do Estado de Mato Grosso } \\ \text { LEB } & \text { Laboratório de Epidemiologia e Bioestatística } \\ \text { MAPA } & \text { Ministério da Agricultura, Pecuária e Abastecimento } \\ \text { MT } & \text { Estado de Mato Grosso } \\ \text { PPD } & \text { Purifieds Proteins Derivates } \\ \text { USP } & \text { Universidade de São Paulo }\end{array}$




\title{
LISTA DE SÍMBOLOS
}

\author{
$\% \quad$ porcentagem \\ $\leq \quad$ menor ou igual a \\ $\chi^{2} \quad$ teste de qui quadrado \\ $<\quad$ menor que \\ $\geq \quad$ maior ou igual a \\ IC intervalo de confiança \\ n tamanho da amostra \\ P prevalência \\ p significância \\ $P_{1} \quad$ peso de cada propriedade \\ $P_{2}$ peso de cada animal
}


SUMÁRIO

1 INTRODUÇÃO

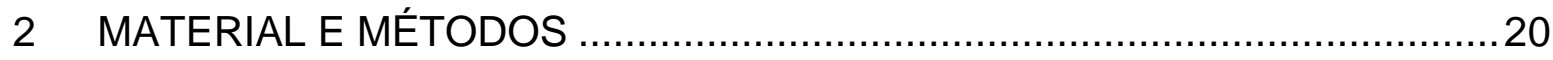

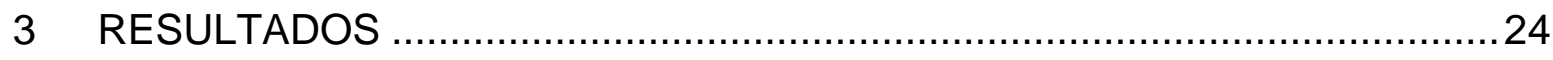

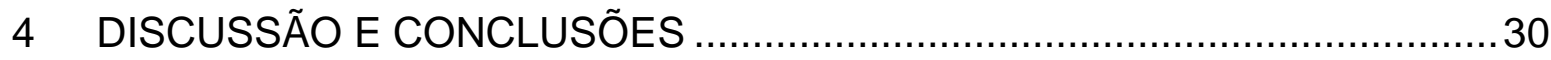

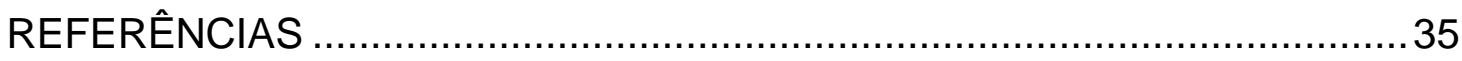

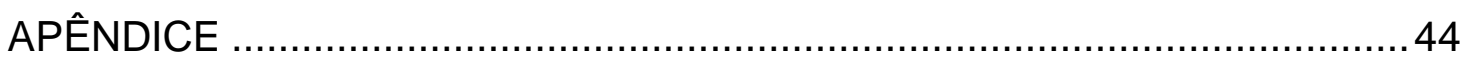


1 INTRODUÇÃO

Localizado na Região Centro Oeste do Brasil o Estado de Mato Grosso (MT) é a terceira maior Unidade Federativa do país com extensão territorial de 903.358 quilômetros quadrados, correspondentes a 9,43\% do território nacional (BRASIL, 2002). Segundo Censo Demográfico 2010 residem no Estado 3.035 .122 habitantes que compõem 1,6\% da população brasileira (BRASIL, 2011a). MT tem sua extensão composta por três biomas: o Amazônia, o Cerrado e o Pantanal que ocupam respectivamente $53,6 \%, 39,6 \%$ e $6,8 \%$ do território mato-grossense. 0 bioma Amazônia localizado na porção Norte e Sudoeste do Estado apresenta vegetação predominantemente florestal; O Cerrado, na porção central reúne formações florestais e principalmente savânicas; Ao Sul o Pantanal apresenta formações savânicas associadas com as florestais monodominantes ou às com grande diversidade de espécies. Este último bioma tem caracteristicamente um pulso de inundação, com níveis de enchente, cheia, vazante e seca, apresentando na estação chuvosa grandes extensões de planície recobertas pela água, enquanto os capões e cordilheiras, unidades de paisagem mais altas, permanecem secos (MATO GROSSO, 2011a).

A bovinocultura foi introduzida em terras mato-grossenses, no período colonial, em áreas pantaneiras situadas entre os rios Taquari e Coxim, favorecida pelas pastagens naturais existentes na região. Atualmente a atividade ocupa boa parte da paisagem do Estado (PIAIA, 2003). Em 2006 as pastagens abrangiam 73,74\% das terras utilizadas, totalizando 21.784 .735 de hectares pertencentes a $71,21 \%$ dos estabelecimentos agropecuários existentes (BRASIL, 2006). Em 2010 um total de 
107.761 propriedades (MATO GROSSO, 2011b) distribuídas nos 141 municípios mato-grossenses (MATO GROSSO, 2010) continha o maior rebanho bovino e bubalino do país com 28.769.469 de cabeças (BRASIL, 2011b). As criações de corte predominam no Estado em quantidade de rebanhos e animais (BRASIL, 2006). De acordo com informações do Ministério da Agricultura Pecuária e Abastecimento (MAPA), em 2010 foram abatidos em Mato Grosso 3.810.056 bovinos (BRASIL, 2010), que representaram $17,4 \%$ do total realizado sob Serviço de Inspeção Federal no Brasil. A atividade leiteira é explorada em 40,8\% dos estabelecimentos (BRASIL, 2006) e em 2009 a produção das 595.394 vacas ordenhadas no Estado foi de aproximadamente 680 milhões de litros, que representaram 2,34\% de todo o leite produzido no Brasil (BRASIL, 2009).

No Brasil, dados de notificação oficiais indicam uma prevalência média para tuberculose de $1,3 \%$, referente a animais reagentes à tuberculina no período de 1989 a 1998 (LAGE et al, 2006). Para MT não foi encontrado nenhum estudo epidemiológico dirigido que tivesse abrangência Estadual, porém a ocorrência da tuberculose em bovinos foi documentada. Entre os anos de 2005 e 2010 foram notificados por Médicos Veterinários habilitados 72 bovinos com testes tuberculínicos positivos (MATO GROSSO, 2011c). Mediante procedimento estabelecido em acordo sanitário internacional firmado com determinados países importadores (BRASIL, 2011c), de 2009 a 2011 foram confirmados 26 casos de tuberculose bovina a partir de amostras coletadas em frigoríficos habilitados para exportação em MT (MATO GROSSO, 2011d). Segundo Salazar (2005), nos anos de 2004 e 2005, dentre 57.641 bovinos abatidos 27 (0,05\%) foram condenados pelo Serviço de Inspeção Estadual devido a lesões sugestivas de tuberculose, dos quais quatro tiveram identificação positiva para Mycobacterium bovis em testes 
moleculares. Em bubalinos a ocorrência da tuberculose foi constatada no Brasil (FREITAS J. A. et al, 2006; FREITAS J. A; PANETTA J. C., 2002; MOTA P. M. P. C. et al, 2002), enquanto para MT não se encontrou nenhum estudo. As pesquisas em animais silvestres de vida livre no país são escassas. Segundo Lobo (2008) não há estudos que confirmem a influência destes animais na reintrodução da doença em rebanhos bovinos. No Estado de Mato Grosso do Sul Luna et al (2003) diante da ausência de achados de necropsia e histopatológicos, bem como de resultados negativos para o complexo $M$. tuberculosis em testes moleculares de 53 cervos do pantanal (Blastocerus dichotomus) concluiu que os mesmos não são disseminadores e provavelmente não tem a doença ativa.

No Brasil a infecção por $M$. bovis parece ter pequena participação nos casos de tuberculose em seres humanos com tendência a um maior risco para pessoas que trabalham com animais susceptíveis por ocasião do manejo ou abate. Kantor et al (2008) confirma a ocorrência de tuberculose bovina em humanos, porém considera sua relevância baixa, advertindo que a pequena cobertura por métodos de cultivo adequados ao isolamento do $M$. bovis contribui para uma subestimativa da doença em seres humanos. Em contra partida Rocha et al (2011) diante da não identificação de $M$. bovis com a utilização de meio de cultura enriquecido com piruvato e/ ou métodos moleculares em amostras clínicas de pacientes suspeitos de tuberculose ( $n$ = 3046) ou tuberculosos $(n=454)$, concluiu que a importância do agente infeccioso em relação à tuberculose humana é marginal no Brasil. Kantor et al (2008) considera ainda que na região composta por 10 países da América Latina, inclusive Brasil, a pasteurização do leite, controles sanitários dos produtos lácteos e a inspeção nos matadouros contribuem para a proteção da saúde humana. Considerando 
entretanto, que a exposição ocupacional continua a ser uma fonte de infecção na região.

O INDEA/ MT controla a distribuição da tuberculina para Médicos Veterinários autônomos no Estado, condicionando seu fornecimento ao encaminhamento de relatórios dos exames realizados. No ano de 2005, em acordo com as normas do Programa Nacional de Controle e Erradicação da Brucelose e Tuberculose, foi estabelecida a habilitação de Médicos Veterinários para a realização de exames de tuberculose e mantida a obrigatoriedade do sacrifício ou destruição de bovinos positivos (LAGE et al, 2006). A certificação de propriedades livres ou monitoradas para a doença, em acordo com o mesmo programa, é voluntária e atualmente não há nenhuma propriedade certificado no Estado (MATO GROSSO, 2011d).

O presente estudo teve como objetivo levantar as prevalências de tuberculose e respectivos fatores de risco em bovinos e bubalinos. Informações importantes ao direcionamento das estratégias de combate à doença no âmbito do Programa Nacional de Controle e Erradicação da Brucelose e Tuberculose em MT. Para tanto, empregaram-se questionários epidemiológicos em amostras representativas de propriedades e animais que foram examinados com a utilização de teste tuberculínico em todos os municípios do Estado. 


\section{MATERIAL E MÉTODOS}

O planejamento do estudo foi realizado em colaboração com o MAPA, o INDEA/ MT e a Faculdade de Medicina Veterinária e Zootecnia (FMVZ) da Universidade de São Paulo (USP). O trabalho de campo foi executado por Médicos Veterinários e Agentes Fiscais do INDEA/ MT nos meses de abril a dezembro de 2009.

Para verificação de possíveis diferenças regionais, tanto nas prevalências da tuberculose, quanto no que se refere aos fatores de risco envolvidos, o estado foi subdividido em quatro regiões com características homogêneas denominadas circuitos produtores. Para esta caracterização, Negreiros et al. (2009) levou em consideração os diferentes sistemas de produção, práticas de manejo, finalidades de exploração, tamanho médio de rebanhos e sistema de comercialização, como também a capacidade operacional e logística do serviço veterinário oficial do Estado para a realização das atividades de campo.

O planejamento amostral foi realizado de maneira a permitir a estimativa das prevalências de focos e de animais nos circuitos produtores e no Estado, através de uma amostragem em dois estágios. No primeiro estágio, dentro de cada circuito produtor, uma quantidade pré-estabelecida de propriedades com atividade reprodutiva foi aleatoriamente selecionada a partir do cadastro de propriedades do INDEA/MT. No segundo estágio, dentro de cada propriedade foi sorteada uma quantidade pré-estabelecida de fêmeas e machos de reprodução com idade igual ou superior a 24 meses. Nas propriedades onde se detectou rebanhos distintos, apenas o predominante foi alvo do estudo, aquele com maior valor econômico ou considerado como principal objetivo da produção. Esse rebanho foi definido como 
um agrupamento de animais mantidos sob as mesmas práticas de manejo, ou seja, expostos a iguais condições de risco. As propriedades sorteadas, mas que por qualquer motivo não puderam ser amostradas foram substituídas por outras, através de novo sorteio. O número de propriedades selecionadas por circuito produtor foi estimado pela fórmula para amostra simples aleatória (THRUSFIELD, 2007), conforme os seguintes parâmetros: Prevalência estimada de 20\%, nível de confiança de $95 \%$ e erro de $5 \%$.

Para o sorteio dos animais dentro de cada propriedade, foi calculada a quantidade de bovinos a ser examinada para classificá-las como foco ou livre de tuberculose, considerando-se os valores de sensibilidade agregada igual ou superior a $85 \%$ e especificidade agregada igual ou superior a $95 \%$. Adotaram-se valores individuais de sensibilidade e especificidade de $80 \%$ e $99,5 \%$, respectivamente. Os cálculos foram realizados com o auxílio do programa Herdacc versão 3.0.

Em propriedade com até 99 fêmeas bovinas ou machos reprodutores com idade igual ou superior a 24 meses, foram examinados 20 animais, ou então todos quando existissem menos do que 20. Em propriedades com 100 ou mais fêmeas e machos de reprodução com idade igual ou superior a 24 meses, foram examinados 40 animais. Esses animais foram sempre selecionados de forma aleatória e excluídas da amostragem as fêmeas em período de periparto, correspondente aos15 dias anteriores e posteriores ao parto.

O teste tuberculínico utilizado foi o cervical comparativo, realizado em conformidade com o Manual Técnico do Programa Nacional de Controle e Erradicação da Brucelose e Tuberculose (LAGE et al, 2006). Os Purifieds Proteins Derivatives (PPD) utilizados, PPD bovino e PPD aviário, foram produzidos pelo Laboratório de Tecnologia do Paraná (TECPAR), em acordo com o estabelecido pela Portaria n.. 64 
de 18 de março de 1994 da Secretaria de Defesa Agropecuária do MAPA. Para evitar que ao término do estudo existissem animais suspeitos ao teste, aqueles que resultaram inconclusivos foram retestados com o mesmo procedimento diagnóstico em intervalo mínimo de 60 dias. Todos os animais positivos foram sacrificados.

Foram classificadas como foco de tuberculose as propriedades com até 20 bovinos amostrados e pelo menos um resultado positivo, assim como, aquelas com 40 animais amostrados e dois ou mais resultados positivos detectados ao procedimento diagnóstico.

Em cada propriedade da amostra foi aplicado um questionário (Apêndice A), planejado de maneira a permitir uma caracterização precisa da tipologia das propriedades e também um estudo dos fatores de risco associados à tuberculose. Com esta finalidade, foram formuladas questões para verificar a existência da condição de exposição aos fatores de risco clássicos já descritos na literatura (MARANGON et al., 1998) e outros de particular interesse regional.

O tratamento dos dados foi realizado no Laboratório de Epidemiologia e Bioestatística (LEB) do Departamento de Medicina Veterinária Preventiva e Saúde Animal (VPS) da FMVZ da USP. Foram obtidas as prevalências de tuberculose bovina para focos e animais no Estado, em cada circuito produtor e de acordo com os tipos de exploração das propriedades, todas expressas na forma de intervalo de confiança (THRUSFIELD, 1995). Os cálculos foram realizados com o auxílio do programa IBM $^{\circledR}$ SPSS $^{\circledR}$ Statistics 20 .

O peso de cada propriedade $\left(P_{1}\right)$ e de cada animal $\left(P_{2}\right)$ para os cálculos das prevalências foram obtidos utilizando-se as seguintes equações.

$$
P_{1}=\frac{\begin{array}{c}
\text { Propriedades com atividade reprodutiva } \\
\text { existentes no circuito }
\end{array}}{\begin{array}{c}
\text { Propriedades com atividade reprodutiva } \\
\text { amostradas no circuito }
\end{array}}
$$




$P_{2}=\frac{\begin{array}{c}\text { Fêmeas } \geq 24 \text { meses } \\ \text { na propriedade }\end{array}}{\begin{array}{l}\text { Reprodutores } \geq 24 \\ \text { meses amostrados }\end{array}} \times \frac{\begin{array}{c}\text { Fêmeas } \geq 24 \text { meses } \\ \text { na região }\end{array}}{}$

O primeiro termo da equação do $P_{2}$ refere-se ao peso de cada animal para ponderação da prevalência de animais dentro de cada circuito produtor.

Em relação ao estudo dos fatores de risco, inicialmente foi realizada uma análise univariada através do teste $\chi^{2}$, com o objetivo de selecionar aquelas com $p \leq 0,20$ para subsequente oferecimento à regressão logística multivariada (HOSMER; LAMESHOW, 1989). Os cálculos foram realizados com o auxílio do programa IBM $^{\circledR}$ SPSS ${ }^{\circledR}$ Statistics 20. 


\section{RESULTADOS}

O Estado foi dividido em quatro circuitos produtores cujos limites podem ser visualizados na figura 1. O circuito pantanal (1) compreende os municípios onde ocorrem extensas áreas atingidas anualmente por pulso de inundação, constituído por enchente, cheia, vazante e seca, onde prevalece a bovinocultura de cria extensiva. No circuito leite (2) ocorre predominância do bioma cerrado, onde foram inclusos municípios com tendência à produção leiteira. No circuito engorda (3), as criações estão voltadas principalmente ao ciclo de engorda e seu espaço está dividido entre os biomas cerrado e floresta amazônica. O circuito cria (4) é constituído por municípios onde o ciclo de cria é mais frequente e sua área situa-se principalmente no bioma floresta amazônica.

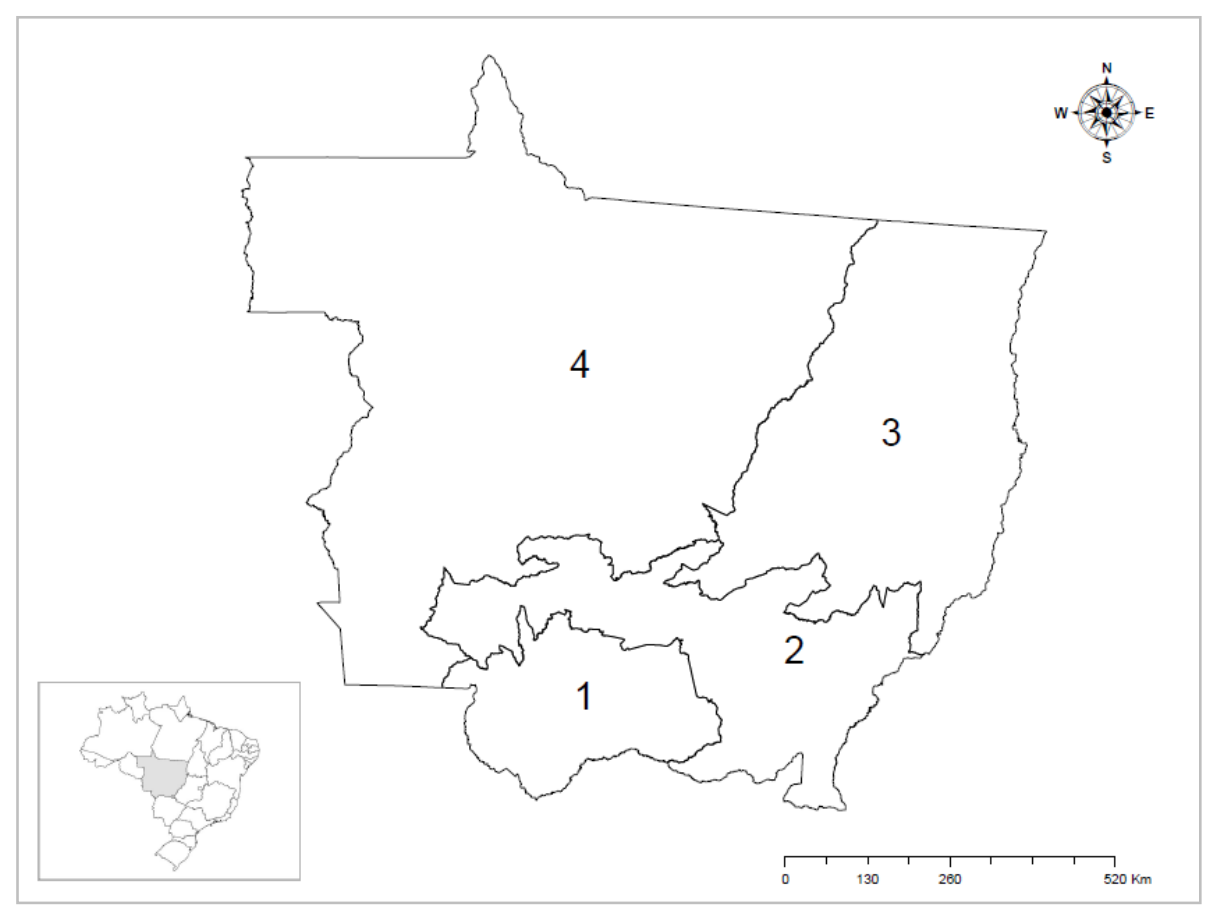

Figura 1 - Mapa do Estado de Mato Grosso com a divisão dos circuitos produtores: pantanal (1), leite (2), engorda (3) e cria (4). No detalhe a localização do Estado no Brasil - São Paulo-2011. 
Na tabela 1 apresenta-se o resumo dos dados censitários e da amostra estudada. Dentre as 1.133 propriedades amostradas, 17 foram desprezadas em função de erros detectados na amostragem ou por impedimentos diversos que impossibilitaram a realização da segunda mensuração da espessura da pele dentro do período estabelecido no procedimento diagnóstico. Devido à pequena quantidade de bubalinos existentes no estado, optou-se por descartar a única propriedade da amostra onde foram examinados 40 bubalinos que resultaram negativos ao teste cutâneo utilizado. As medianas para o tamanho do rebanho em propriedades do tipo corte, misto e leite e foram de 306, 160 e 51 bovinos, respectivamente.

Tabela 1 - Resumo censitário do efetivo bovino e detalhes da amostra estudada, segundo os circuitos produtores- Mato Grosso - 2011

\begin{tabular}{lccccc}
\hline $\begin{array}{c}\text { Circuito } \\
\text { Produtor }\end{array}$ & $\begin{array}{c}\text { Total de } \\
\text { municípios }\end{array}$ & $\begin{array}{c}\text { Total de } \\
\text { propriedades } \\
\text { com atividade } \\
\text { reprodutiva }\end{array}$ & $\begin{array}{c}\text { Propriedades } \\
\text { amostradas }\end{array}$ & $\begin{array}{c}\text { Total de } \\
\text { fêmeas com } \\
\text { idade } \geq 24 \\
\text { meses }\end{array}$ & $\begin{array}{c}\text { Fêmeas e } \\
\text { machos } \\
\text { reprodutores } \\
\text { amostrados }\end{array}$ \\
\hline $\begin{array}{l}1-\text { Pantanal } \\
\text { 2- Leite }\end{array}$ & 6 & 6.836 & 146 & 1.021 .778 & 3.938 \\
$3-$ Engorda & 27 & 22.878 & 387 & 2.249 .231 & 9.462 \\
$4-$ Cria & 58 & 45.615 & 298 & 5.486 .549 & 7.545 \\
Total & 141 & 93.296 & 1.133 & 11.643 .518 & 28.878
\end{tabular}

Fonte: Secretaria de Desenvolvimento Rural e Agricultura Familiar. Instituto de Defesa Agropecuária do Estado de Mato Grosso (INDEA/ MT), 2009

$\mathrm{Na}$ tabela 2 mostram-se os resultados referentes à prevalência de focos de tuberculose bovina nos circuitos produtores e no Estado. A prevalência de focos por tipo de exploração nos circuitos produtores está apresentada na tabela 3 e a prevalência de tuberculose bovina para fêmeas e machos de reprodução com idade igual ou superior a 24 meses na tabela 4. 
Tabela 2 - Prevalência de focos de tuberculose bovina e respectivo intervalo de confiança (IC) por circuito produtor e para o Estado - Mato Grosso - 2011

\begin{tabular}{lcccc}
\hline \multirow{2}{*}{ Circuito Produtor } & \multicolumn{2}{c}{ Propriedades } & Prevalência (\%) & IC 95\% (\%) \\
\cline { 2 - 3 } & Examinadas & Positivas & & \\
\hline 1 - Pantanal & 146 & 0 & 0,0 & ${ }^{(1)}[0,0 ; 2,0]$ \\
2 - Leite & 387 & 5 & 1,3 & {$[0,5 ; 3,1]$} \\
$3-$ Engorda & 302 & 2 & 0,7 & {$[0,2 ; 2,7]$} \\
$4-$ Cria & 298 & 5 & 1,7 & {$[0,7 ; 4,1]$} \\
Mato Grosso & 1.133 & 12 & 1,3 & {$[0,7 ; 2,4]$} \\
\hline
\end{tabular}

(1) Cálculo realizado utilizando o método de Monte Carlo e a distribuição beta

Tabela 3 - Prevalência de focos de tuberculose bovina estratificada por tipo de exploração nos circuitos produtores Mato Grosso - 2011

\begin{tabular}{|c|c|c|c|c|c|c|}
\hline \multirow[b]{3}{*}{ Circuito produtor } & \multicolumn{6}{|c|}{ Prevalência de focos de tuberculose $(P)$} \\
\hline & \multicolumn{2}{|c|}{ Corte } & \multicolumn{2}{|c|}{ Leite } & \multicolumn{2}{|c|}{ Misto } \\
\hline & $\begin{array}{c}\mathrm{P}(\%) \\
\text { (Positivas/ } \\
\text { examinadas) }\end{array}$ & $\begin{array}{c}\text { IC 95\% } \\
(\%)\end{array}$ & $\begin{array}{c}\mathrm{P}(\%) \\
\text { (Positivas/ } \\
\text { examinadas) }\end{array}$ & $\begin{array}{c}\text { IC 95\% } \\
(\%)\end{array}$ & $\begin{array}{c}\mathrm{P}(\%) \\
\text { (Positivas/ } \\
\text { examinadas) }\end{array}$ & IC 95\% (\%) \\
\hline 1 - Pantanal & $0,0(0 / 94)$ & ${ }^{(1)}[0,0 ; 3,1]$ & $0,0(0 / 28)$ & ${ }^{(1)}[0,0 ; 9,8]$ & $0,0(0 / 23)$ & (1) $[0,0 ; 11,7]$ \\
\hline 2 - Leite & $0,0(0 / 157)$ & ${ }^{(1)}[0,0 ; 1,9]$ & $2,7(4 / 148)$ & {$[1,0 ; 7,0]$} & $1,3(1 / 76)$ & {$[0,2 ; 8,8]$} \\
\hline 3 - Engorda & $0,0(0 / 209)$ & ${ }^{(1)}[0,0 ; 1,4]$ & $2,1(1 / 47)$ & {$[0,3 ; 13,7]$} & $2,4(1 / 42)$ & {$[0,3 ; 15,1]$} \\
\hline $4-$ Cria & $0,6(1 / 161)$ & {$[0,1 ; 4,3]$} & $3,2(3 / 94)$ & {$[1,0 ; 9,5]$} & $2,8(1 / 36)$ & {$[0,4 ; 17,3]$} \\
\hline
\end{tabular}

(1) Cálculo realizado utilizando o método de Monte Carlo e a distribuição beta

Tabela 4 - Prevalência de bovinos fêmeas e machos reprodutores com idade $\geq 24$ meses positivos para tuberculose e respectivo intervalo de confiança (IC) por circuito produtor e para o Estado - Mato Grosso - 2011

\begin{tabular}{lcccc}
\hline \multirow{2}{*}{ Circuito Pecuário } & \multicolumn{2}{c}{ Animais } & Prevalência (\%) & IC (95\%) (\%) \\
\cline { 2 - 3 } & Examinados & Positivos & & \\
\hline 1 - Pantanal & 3.938 & 0 & 0,000 & ${ }^{(1)}[0,000 ; 0,076]$ \\
2 - Leite & 9.462 & 12 & 0,037 & {$[0,008 ; 0,168]$} \\
3 - Engorda & 7.933 & 3 & 0,010 & {$[0,003 ; 0,043]$} \\
$4-$ Cria & 7.545 & 8 & 0,240 & {$[0,064 ; 0,904]$} \\
Mato Grosso & 28.878 & 23 & 0,123 & {$[0,034 ; 0,440]$} \\
\hline
\end{tabular}

(1) Cálculo realizado utilizando o método de Monte Carlo e a distribuição beta 
A tabela 5 traz os resultados da análise univariada. Devido à pequena quantidade de casos detectados (12 focos) nenhum dos modelos de regressão logística pesquisados apresentou-se viável.

Tabela 5 - Resultados da análise univariada dos possíveis fatores de risco para tuberculose bovina que resultaram em $p \leq 0,20$ - Mato Grosso - 2011

\begin{tabular}{|c|c|c|c|c|c|c|}
\hline Variável e categorias & Neg. & Pos. & Total & $\%$ & $\chi^{2}$ & $p$ \\
\hline Tipo de ordenha & & & & & 26,2 & (3) $<0,001$ \\
\hline (1) Não ordenha & 564 & 0 & 564 & 0,0 & & \\
\hline Em sala & 14 & 3 & 17 & 17,6 & & \\
\hline Mecânica ao pé & 22 & 0 & 22 & 0,0 & & \\
\hline Manual & 500 & 9 & 509 & 1,8 & & \\
\hline Quantidade de ordenhas & & & & & 15,1 & (2) $<0,001$ \\
\hline (1) Não ordenha & 559 & 0 & 559 & 0,0 & & \\
\hline Uma ordenha & 493 & 11 & 504 & 2,2 & & \\
\hline Duas ou três ordenhas & 41 & 1 & 42 & 2,4 & & \\
\hline Tipo de exploração & & & & & 11,8 & 0,003 \\
\hline (1) Corte & 620 & 1 & 621 & 0,2 & & \\
\hline Leite & 309 & 8 & 317 & 2,5 & & \\
\hline Misto & 174 & 3 & 177 & 1,7 & & \\
\hline Raça bovina predominante & & & & & 9,6 & (3) 0,003 \\
\hline (1) Zebuínas & 680 & 2 & 682 & 0,3 & & \\
\hline Mestiças & 386 & 9 & 395 & 2,3 & & \\
\hline Entrega do leite a granel & & & & & 8,0 & ${ }^{(3)} 0,005$ \\
\hline (1) Não & 939 & 6 & 945 & 0,6 & & \\
\hline Sim & 165 & 6 & 171 & 3,5 & & \\
\hline $\begin{array}{l}\text { Tipo de ordenha em propriedades } \\
\text { dos tipos corte e misto }\end{array}$ & & & & & 9,1 & ${ }^{(3)} 0,006$ \\
\hline (1) Manual & 442 & 8 & 450 & 1,8 & & \\
\hline Mecânica ao pé & 22 & 0 & 22 & 0,0 & & \\
\hline Mecânica em sala & 14 & 3 & 17 & 17,6 & & \\
\hline Entrega de leite & & & & & 7,8 & ${ }^{(3)} 0,006$ \\
\hline (1) Não & 714 & 3 & 717 & 0,4 & & \\
\hline Sim & 390 & 9 & 399 & 2,3 & & \\
\hline Raça bovina predominante & & & & & 11,3 & (3) 0,011 \\
\hline (1) Zebuínas & 680 & 2 & 682 & 0,3 & & \\
\hline Européias de leite & 20 & 1 & 21 & 4,8 & & \\
\hline Européias de corte & 6 & 0 & 6 & 0,0 & & \\
\hline Mestiças & 386 & 9 & 395 & 2,3 & & \\
\hline Outras Raças & 8 & 0 & 8 & 0,0 & & \\
\hline
\end{tabular}




\begin{tabular}{|c|c|c|c|c|c|c|}
\hline Variável e categorias & Neg. & Pos. & Total & $\%$ & $\chi^{2}$ & $p$ \\
\hline Resfriamento do leite & & & & & 5,5 & (3) 0,018 \\
\hline (1) Não & 952 & 7 & 959 & 0,7 & & \\
\hline Sim & 152 & 5 & 157 & 3,2 & & \\
\hline Quartil de rebanho total & & & & & 8,7 & ${ }^{(3 ; 4)} 0,028$ \\
\hline (1) 1 a 55 & 279 & 3 & 282 & 1,1 & & \\
\hline 56 a 141 & 274 & 2 & 276 & 0,7 & & \\
\hline 142 a 486 & 272 & 7 & 279 & 2,5 & & \\
\hline 487 a 16.957 & 279 & 0 & 279 & 0,0 & & \\
\hline $\begin{array}{l}\text { Realização de testes para diagnóstico } \\
\text { de tuberculose }\end{array}$ & & & & & 4,3 & ${ }^{(3)} 0,035$ \\
\hline (1) Não & 1027 & 8 & 1035 & 0,8 & & \\
\hline Sim & 74 & 3 & 77 & 3,9 & & \\
\hline Gatos domésticos (proteção) & & & & & 3,3 & ${ }^{(3)} 0,060$ \\
\hline (1) Não & 359 & 7 & 366 & 1,9 & & \\
\hline Sim & 745 & 5 & 750 & 0,7 & & \\
\hline Abate na própria fazenda & & & & & 2,9 & ${ }^{(3)} 0,077$ \\
\hline${ }^{(1)}$ Não & 789 & 7 & 796 & 0,9 & & \\
\hline Sim & 143 & 4 & 147 & 2,7 & & \\
\hline $\begin{array}{l}\text { Ingresso de bovinos ou bubalinos } \\
\text { nos últimos dois anos }\end{array}$ & & & & & 2,7 & 0,089 \\
\hline${ }^{(1)}$ Não & 536 & 3 & 539 & 0,6 & & \\
\hline Sim & 566 & 9 & 575 & 1,6 & & \\
\hline $\begin{array}{l}\text { Produz queijo ou manteiga para } \\
\text { consumo próprio }\end{array}$ & & & & & 2,9 & ${ }^{(3)} 0,090$ \\
\hline (1) Não & 34 & 2 & 36 & 5,6 & & \\
\hline Sim & 370 & 4 & 374 & 1,1 & & \\
\hline Cervídeos selvagens & & & & & 2,2 & 0,114 \\
\hline${ }^{(1)}$ Não & 497 & 8 & 505 & 1,6 & & \\
\hline Sim & 607 & 4 & 611 & 0,7 & & \\
\hline Veterinário de cooperativa & & & & & 2,6 & (3) 0,116 \\
\hline${ }^{(1)}$ Não & 198 & 2 & 200 & 1,0 & & \\
\hline Sim & 35 & 2 & 37 & 5,4 & & \\
\hline Veterinário particular & & & & & 2,6 & ${ }^{(3)} 0,116$ \\
\hline (1) Não & 35 & 2 & 37 & 5,4 & & \\
\hline Sim & 198 & 2 & 200 & 1,0 & & \\
\hline Entrega leite em cooperativa & & & & & 1,8 & (3) 0,151 \\
\hline (1) Não & 297 & 5 & 302 & 1,7 & & \\
\hline Sim & 93 & 4 & 97 & 4,1 & & \\
\hline
\end{tabular}




\begin{tabular}{|c|c|c|c|c|c|c|}
\hline Variável e categorias & Neg. & Pos. & Total & $\%$ & $\chi^{2}$ & $p$ \\
\hline $\begin{array}{l}\text { Produz queijo ou manteiga para } \\
\text { venda } \\
\text { (1) Não }\end{array}$ & 357 & 4 & 361 & 1,1 & 1,9 & (3) 0,154 \\
\hline Sim & 47 & 2 & 49 & 4,1 & & \\
\hline Suídeos domésticos & & & & & 1,5 & 0,174 \\
\hline (1) Não & 565 & 4 & 569 & 0,7 & & \\
\hline Sim & 539 & 8 & 547 & 1,5 & & \\
\hline $\begin{array}{l}\text { Adquiriu bovinos e bubalinos em } \\
\text { fazendas }\end{array}$ & & & & & 3,5 & (3) 0,177 \\
\hline (1) Não & 100 & 0 & 100 & 0,0 & & \\
\hline Sim & 466 & 9 & 475 & 1,9 & & \\
\hline Marsupiais selvagens & & & & & 1,4 & 0,185 \\
\hline (1) Não & 639 & 9 & 648 & 1,4 & & \\
\hline Sim & 465 & 3 & 468 & 0,6 & & \\
\hline Produz queijo ou manteiga & & & & & 1,3 & ${ }^{(3)} 0,193$ \\
\hline (1) Não & 679 & 5 & 684 & 0,7 & & \\
\hline $\operatorname{Sim}$ & 404 & 6 & 410 & 1,5 & & \\
\hline Assistência veterinária & & & & & 1,3 & ${ }^{(3)} 0,195$ \\
\hline${ }^{(1)}$ Não & 859 & 7 & 866 & 0,8 & & \\
\hline Sim & 233 & 4 & 237 & 1,7 & & \\
\hline
\end{tabular}

(1) Categoria de referência. (2) Teste Exato de Fisher. (3) Teste G. (4) Proteção 


\section{DISCUSSÃO E CONCLUSÕES}

A prevalência de focos de tuberculose bovina para o Estado de MT foi estimada em $1,3 \%[0,7 ; 2,4 \%]$ e não foi possível constatar diferenças entre os circuitos produtores; todavia, os resultados sugerem maior concentração da doença na região composta pelos circuitos leite, engorda e cria quando comparada com o pantanal (tabela 2). Diante da não observância de pesquisa direcionada ao levantamento de focos em MT, compara-se o resultado obtido com equivalente estudo desenvolvido por Belchior (2000), que englobou 75\% dos rebanhos bovinos do Estado de Minas Gerais e estimou a prevalência de focos em 5,02\% [4,67\%; 5,37\%]. O resultado estatisticamente superior ao de MT pode ter sido consequência de diferenças nas predominâncias dos tipos de exploração e sistemas de criação dos Estados, características que influenciam a manutenção e espalhamento da tuberculose bovina. Dos 14 Estados do Centro-Sul brasileiro pesquisados por Braga (2010), MT figurou entre os dois únicos com proporção de propriedades restritas ao corte significativamente maior que os outros tipos de exploração, com 55,43\% [52,13\%; 58,68\%], enquanto no Estado de Minas Gerais houve predominância de propriedades do tipo leite, com 56,36\% [54,20\%; 58,5\%]. Braga (2010) verificou ainda que as criações extensivas são mais frequentes em Mato Grosso $(92,02 \%)$ do que em Minas Gerais (59,82\%). A associação entre tuberculose bovina e a atividade leiteira foi constatada por diversos autores (BELCHIOR, 2000; PEREZ et al, 2002; PORPHYRE; STEVENSON; MCKENZIE, 2008; RAMÍREZ-VILLAESCUSA et al, 2010; ZENDEJAS-MARTÍNEZ, 2007; ZENDEJAS-MARTÍNEZ; TOWNSEND; MILIÁNSUAZO, 2008) e isso pode ser atribuído a fatores inerentes a este tipo de exploração, 
descritos como predisponentes a doença, tais como, densidade (CLEAVELAND et al, 2007; HUMBLET et al, 2010; OLIVEIRA et al, 2008) e ciclo produtivo mais longo (AMENI et al 2007; BALAKO et al 2011; BIFFA et al, 2011; BONSU; LAING; AKANMORI, 2000; INANGOLET et al, 2008; JAVED et al, 2011; KAZWALA et al, 2001; MUNYEME et al 2009; REGASSA et al, 2010). Em sua pesquisa Braga (2010) verificou ainda que na maior parte das propriedades do tipo corte e misto os bovinos são criados de forma extensiva, com respectivos resultados de $94,33 \%[93,4 \%$; $95,13 \%]$ e $80,14 \% \quad[74,72 \% ; 86,28 \%]$, enquanto nos estabelecimentos exclusivamente de leite encontrou as menores proporções deste sistema de criação, com $58,61 \%$ [57,05\%; $60,15 \%]$. As menores prevalências para propriedades do tipo corte em todos os circuitos produtores, exceto no pantanal (tabela 3), embora não sejam estatisticamente significantes, sugerem fortemente uma associação entre a tuberculose bovina e a atividade leiteira em MT.

No Estado de MT a prevalência de tuberculose em bovinos fêmeas e machos reprodutores com idade $\geq 24$ meses foi estimada em $0,123 \%[0,034 ; 0,440 \%]$ e sua distribuiçãofoi relativamente homogênea entre os circuitos produtores, com exceção do circuito engorda onde o resultado foi estatisticamente inferior ao circuito cria (tabela 4). O que pode ser explicado pela maior proporção de propriedades do tipo corte neste circuito (70\%) em relação aos demais: pantanal (65\%), leite (41\%) e cria (55\%). Em que pese o fato de não existir outra pesquisa envolvendo todo o Estado e com planejamento amostral comparável ao utilizado no presente estudo, resultados semelhantes foram observados por Salazar (2005), que mediante verificação de achados compatíveis com tuberculose ao exame post mortem em 57.641 bovinos oriundos de 13 municípios localizados nas regiões Centro-Norte e Sudeste de MT estimou a ocorrência da doença em $0,05 \%$, e por Shenck M. A. M. e Shenck J. A. P. 
(1982) que entre 1,7 milhão de bovinos abatidos verificaram $0,2 \%$ com lesões sugestivas de tuberculose no Mato Grosso do Sul, Estado que apresenta características muito parecidas com as de MT. Mesmo diante das similaridades geográficas dos Estados, qualquer comparação deve ser precedida de considerações relativas às diferenças nas metodologias empregadas, principalmente no que se refere às amostragens e testes utilizados. Embora o valor pontual da prevalência de animais estimada no presente estudo, 0,123\% [0,034\%;0,440\%] (tabela 4), seja menor que o de Minas Gerais em 1999, 0,81\% [0,37\%; 1,25\%] (Belchior, 2000), a sobreposição dos intervalos de confiança não permite dizer que sejam diferentes. Uma amostra mais precisa provavelmente detectaria essa diferença.

O pequeno número de casos detectados (12) inviabilizou um estudo completo para individualização dos fatores de risco envolvidos, restando para a pesquisa somente os testes de associação $\left(\chi^{2}\right)$ empregados na análise univariada. A entrega de leite e os tipos de exploração leite e misto estiveram associados com a condição de foco, o que reforça as constatações discutidas acima sobre a influência dos fatores inerentes a produção leiteira na epidemiologia da tuberculose no Estado. O tamanho do rebanho que em outras pesquisas foi descrito como fator associado (BIFFA et al, 2011; CADMUS et al, 2010; CARRIQUE-MAS; MEDLEY; GREEN, 2008; CLEAVELAND et al, 2007; KANEENE et al, 2002; LILENBAUM; SOUZA; FONSECA, 2007; PORPHYRE et al, 2008; PROAÑO-PEREZ et al, 2006; RAMÍREZVILLAESCUSA et al, 2010) resultou em MT como fator de proteção (tabela 5). Essa discrepância pode ser explicada pela forte associação $(p<0,001)$ entre propriedades com rebanho geral $\geq 487$ cabeças e o tipo de exploração corte (dados não apresentados). O mesmo ocorreu com a variável raça predominante, considerando 
que as raças mais frequentes entre as propriedades amostradas, zebuínas (61\%) e mestiças (36\%), estiveram fortemente associadas com corte e leite respectivamente $(p<0,001)$ (dados não apresentados). Verificando-se ainda independência desta variável em relação à condição de foco quando avaliada no grupo composto por propriedades dos tipos leite e misto separadamente do corte (dados não apresentados). A associação da realização de testes para diagnóstico de tuberculose com a condição de foco (tabela 5) pode ser relacionada a um padrão de propriedades com maior movimentação de animais, tendo em vista que sua utilização nas propriedades amostradas ocorria principalmente em função do atendimento da obrigatoriedade no trânsito interestadual, em eventos agropecuários e no crédito destinado à comercialização de bovinos. Observando-se que os testes regulares que possibilitariam a prevenção ou controle da doença eram praticados em apenas $8 \%$ das 77 propriedades com realização de testes da amostra.

As variáveis relativas à atividade leiteira que no conjunto maior de propriedades resultaram associadas à condição de foco também foram analisadas no grupo composto por propriedades dos tipos leite e misto para verificação da influência do nível de tecnificação em relação a essas tipologias (tabela 5). Nesta avaliação a quantidade de ordenhas, entrega do leite a granel e resfriamento do leite perderam suas significâncias e resultaram independentes (dados não apresentados), enquanto, em concordância com estudo de Belchior (2000) a utilização de ordenha mecanizada permaneceu associada à condição de foco (tabela 5).

Não foram incluídas na análise multivariada $(p>0,20)$ as variáveis: tipo de criação (confinado, semiconfinado ou extensivo), quantidade de vacas em lactação, produção diária de leite, uso de inseminação artificial, outras espécies domésticas (ovinos/ caprinos, eqüídeos, aves comerciais e cão), presença de espécies silvestres 
de vida livre, presença de capivaras, pastagem fazendo divisa com mata, realização de tuberculinização antes do ingresso de bovinos/ bubalinos na propriedade, procedência dos bovinos ou bubalinos ingressados nos últimos 2 anos (exposição, leilão/feira ou comerciante de gado), realização de abate, local de abate de fêmeas e machos adultos no fim da vida reprodutiva (estabelecimento sem ou com inspeção), aluguel de pastagem, pastagem em comum com outras propriedades, acesso dos animais a áreas alagadiças, compartilhamento de itens com outras propriedades, destinação do leite (laticínio ou direto ao consumidor), alimentação de bovinos com soro de leite bovino e compra ou venda de bovinos nos últimos doze meses (dados não apresentados).

Em MT as prevalências de tuberculose bovina, tanto de focos quanto de animais, são baixas e a infecção está mais concentrada em propriedades de leite com maior grau de tecnificação no modo de produção. Em vista disso, a implementação de um sistema de vigilância para detecção e saneamento dos focos residuais constitui a melhor alternativa para o controle da doença no Estado. 
REFERÊNCIAS

ADALGIZA, R.; ELIAS, A. R.; SOBRAL, L. F.; SOARES, D. F.; SANTOS, A. C.; MARSICO, A. G.; HACKER, M. A.; CALDAS, P. C.; PARENTE, L. C.; SILVA, M. R.; FONSECA, L.; SUFFYS, P; BOÉCHAT, N. Genotyping did not evidence any contribution of Mycobacterium bovis to human tuberculosis in Brazil. Tuberculosis, [S. I.], v. 91, 14-21, 2011.

AMENI, G.; ASEFFA, A.; ENGERS, H.; YOUNG, D.; GORDON, S.; HEWINSON, G.; VORDERMEIER, M. High prevalence and increased severity of pathology of bovine tuberculosis in holsteins compared to zebu breeds under field cattle husbandry in Central Ethiopia. Clinical and Vaccine Immunology, [S.I.], v. 14, n. 10, p. 1356-1361, out. 2007.

Belchior, A. P. C. Prevalência, distribuição regional e fatores de risco da tuberculose bovina em Minas Gerais. 2000. 55 f. (Mestrado em Medicina Veterinária) - Escola de Veterinária, Universidade Federal de Minas Gerais, Belo Horizonte, 2000.

BIFFA, D.; INANGOLET, F.; BOGALE, A.; OLOYA, J.; DJØNNE, B.; SKJERVE, E. Risk factors associated with prevalence of tuberculosis-like lesions and associated mycobacteria in cattle slaughtered at public and export abattoirs in Ethiopia. Tropical Animal Health and Production, [S.I.], v. 43, p. 529-538, 2011.

BONSU, O. A.; LAING, E.; AKANMORI, B. D. Prevalence of tuberculosis in cattle in the Dangme-West district of Ghana, public health implications. Acta Tropica, [S.I.], v. 76, p. 9-14, 2000.

Braga, G. B. Caracterização dos sistemas de criação de bovinos com atividade reprodutiva e estimativa da prevalência da brucelose bovina na Região CentroSul do Brasil. 2010. 206 f. Dissertação (Mestrado em Ciências) - Faculdade de Medicina Veterinária e Zootecnia, Universidade de São Paulo, São Paulo, 2010. 
BRASIL. Ministério da Agricultura Pecuária e Abastecimento. Secretaria de Defesa Agropecuária. Departamento de Saúde Animal. Coordenação Geral de Combate às Doenças. Rebanho Bovino e Bubalino do Brasil, 2010. Brasília, 2010. Disponível em: <http://www.agricultura.gov.br/arqeditor/file/Animal/programa\%20nacional\%20 sanidade\%20aftosa/Rebanho\%20nacional_2010.pdf>. Acesso em 24 de agosto de 2011b.

BRASIL. Ministério da Agricultura Pecuária e Abastecimento. Secretaria de Defesa Agropecuária. Departamento de Inspeção de Produtos de Origem Animal. Sistema de Informações Gerenciais do Serviço de Inspeção Federal. Situação 2011. Brasília: DIPOA, 2010.

BRASIL. Ministério da Agricultura Pecuária e Abastecimento. Secretaria de Defesa Agropecuária. Departamento de Inspeção de Produtos de Origem Animal/ Departamento de Saúde Animal. Fax Circular Conjunto DIPOA/ DSA 001/2011. Revoga o Fax Circular Conjunto CGAL/ DIPOA/ DSA 001 de 11 de fevereiro de 2009. Brasília, 01 de julho de 2011c.

BRASIL. Ministério do Planejamento, Orçamento e Gestão. Instituto Brasileiro de Geografia e Estatísticas. Rio de Janeiro, 2002. Resolução № 05, de 10 de outubro de 2002. Diário Oficial da União № 198 - Seção 1, de 11 de outubro de 2002. p. 48 à 65 .

BRASIL. Ministério do Planejamento, Orçamento e Gestão. Instituto Brasileiro de Geografia e Estatísticas. Sinopse do Censo Demográfico 2010: Brasil, Grandes Regiões e Unidades da Federação. Rio de Janeiro: IBGE, 2011a. 261 p.

BRASIL. Ministério do Planejamento, Orçamento e Gestão. Instituto Brasileiro de Geografia e Estatísticas. Censo Agropecuário 2006: Brasil, Grandes Regiões e Unidades da Federação. Rio de Janeiro: IBGE, 2006. 777 p. 
BRASIL. Ministério do Planejamento, Orçamento e Gestão. Instituto Brasileiro de Geografia e Estatísticas. Diretoria de Pesquisa. Coordenação de Agropecuária. Produção Pecuária Municipal. Rio de Janeiro: IBGE, 2009. v. 37, p.1-55.

CADMUS, S. I. B.; AGADA, C. A.; ONOJA, I. I.; SALISU, I. Risk factors associated with bovine tuberculosis in some selected herds in Nigeria. Tropical Animal Health and Production, [S.I.], v. 42, p. 547-549, 2010.

CARRIQUE-MAS, J. J.; MEDLEY, G. F; GREEN, L. E. Risks for bovine tuberculosis in british cattle farms restocked after the foot and mouth disease epidemic of 2001. Preventive Veterinary Medicine, [S.I.], v. 84, p. 85-93, 2008.

CLEAVELAND, S.; SHAW, D. J.; MFINANGA, S. G.; SHIRIMAD, G.; KAZWALA, R. R.; EBLATE, E.; SHARP, M. Mycobacterium bovis in rural Tanzania: Risk factors for infection in human and cattle populations. Tuberculosis, [S.I.], v. 87, p. 30-43, 2007.

DRISCOLL, E. E.; HOFFMAN, J. I.; GREEN, L. E; MEDLEY, G. F.; AMOS, W. A preliminary study of genetic factors that influence susceptibility to bovine tuberculosis in the british cattle herd. Bielefeld, Plos One, v. 6, i. 4, e18806, 9 p., Abr. 2011.

FREITAS J. A., JOSE CEZAR PANETTA. Some epidemiological aspects of tuberculosis in water buffaloes in the amazon basin of Brazil. Buffalo Bulletin, [S. I.] v. 21, n. 4,2002

FREITAS, J. A.; AGUIAR, R. V. de; PEDROSO, S. C. S.; BARROSO, R.; MONTEIRO, F. J. C. Levantamento da ocorrência de tuberculose e brucelose em rebanhos leiteiros no Estado do Pará. Revista de Ciências Agrárias, Belém, n. 46 , p. 227-237, 2006 
GUMI, B.; SCHELLING, E.; FIRDESSA, R.; ASEFFA, A.; TSCHOPP, R.; YAMUAH, L.; YOUNG, D.; ZINSSTAG, J. Prevalence of bovine tuberculosis in pastoral cattle herds in the Oromia region, Southern Ethiopia. Tropical Animal Health and Production, [S.I.], v. 43, n. 6, p. 1081-1087, 2011.

HOSMER, D.W.; LAMESHOW, S. Applied logistic regression. New York: John Wiley and Sons, 1989. 307 p.

HUMBLET, M. F.; GILBERT, M.; GOVAERTS, M.; FAUVILLE-DUFAUX, M.; WALRAVENS, K.; SAEGERMAN, C. New assessment of bovine tuberculosis risk factors in Belgium based on nationwide molecular epidemiology. Journal of Clinical Microbiology, [S.I.], v. 48, n. 8, p. 2802-2808, Ago. 2010.

INANGOLET, F. O.; DEMELASH, B.; OLOYA, J.; OPUDA-ASIBO J.; SKJERVE, E. A cross-sectional study of bovine tuberculosis in the transhumant and agropastoral cattle herds in the border areas of Katakwi and Moroto districts, Uganda. Tropical Animal Health and Production, [S.I.], v. 40, p. 501-508, 2008.

JAVED, M. T.; IRFAN, M.; ALI, I.; FAROOQI, F. A.; WASIQ, M.; CAGIOLA, M. Risk factors identified associated with tuberculosis in cattle at 11 livestock experiment stations of Punjab Pakistan. Acta Tropica, [S.I.], v. 117, p. 109-113, 2011.

KANEENE, J. B.; BRUNING-FANN, C. S.; GRANGER, L. M.; MILLER, R.; PORTERSPALDING. B. A. Environmental and farm management factors associated with tuberculosis on cattle farms in Northeastern Michigan. Journal of the American Veterinary Medical Association, [S.I.], v. 221, n. 6, p. 837-842, Set. 2002.

KANTOR, I. N. DE; AMBROGGI, M.; POGGI, S.; MORCILLO, N.; SILVA TELLES, M. A. DA; OSÓRIO, R. M.; GARZÓN, T. M. C.; LLERENA, P. C.; RIBÓN, W.; GARCÍA, V.; KUFFO, D.; ASENCIOS, L.; VÁSQUEZ CAMPOS, L. M.; RIVAS, C.; WAARD, 
J.H. DE. Human Mycobacterium bovis infection in ten Latin American countries. Tuberculosis, [S. I], v. 88, p. 358-365, 2008

KAZWALA, R. R.; KAMBARAGE, D. M.; DABORN, C. J.; NYANGE, J.; JIWA, S. F. H.; SHARP, J. M. Risk factors associated with the occurrence of bovine tuberculosis in cattle in Southern Highlands of Tanzania. Veterinary Research Communications, [S.I.], v. 25, p. 609-614, 2001.

LAGE, A. P.; ROXO, E.; MÜLLER, E.; POESTER, F.; CAVALLÉRO, J.C.M.; FERREIRA NETO, J.S.; MOTA, P.M.P.C.; GONÇALVES, V.S.P. Programa nacional de controle e erradicação da brucelose e da tuberculose animal (PNCEBT): Manual técnico. Brasília: Ministério da Agricultura, Pecuária e Abastecimento (MAPA), 2006, $184 \mathrm{p}$.

LAGE, A.P.; ROXO, E.; MÜLLER, E.; POESTER, F.; CAVALLÉRO, J.C.M.; FERREIRA NETO, J.S.; MOTA, P.M.P.C.; GONÇALVES, V.S.P. Programa nacional de controle e erradicação da brucelose e da tuberculose animal (PNCEBT): Manual técnico. Brasília: Ministério da Agricultura, Pecuária e Abastecimento (MAPA), 2006, $184 \mathrm{p}$.

LILENBAUM, W.; SOUZA, G. N. de; FONSECA, L. de S. Fatores de manejo associados à ocorrência de tuberculose bovina em rebanhos leiteiros do Rio de Janeiro, Brasil. Revista Brasileira de Ciência Veterinária, v. 14, n. 2, p. 98-100, set. 2007.

LÔBO J. R. Análise custo-benefício da certificação de propriedades livres de tuberculose bovina. 2008. 84 f. Dissertação (Mestrado em Agronegócios) Faculdade de Agronomia e Medicina Veterinária, Universidade de Brasília, Brasília, 2008

LUNA, J. O; SANTOS, M. A. A.; DURIGON, E. L.; ARAÚJO JÚNIOR, J. P.; DUARTE, J. M. B. Tuberculosis survey of free-ranging marsh deer (Blastocerus 
dichotomus) in Brazil. Journal of Zoo and Wildlife Medicine, [S. I.], v. 34(4), p. 414415, 2003

MARANGON, S.; MARTINI, M.; DALLA POZZA, M.; FERREIRA NETO, J.S. A casecontrol study on bovine tuberculosis in the Veneto region, Italy. Preventive Veterinary Medicine, v. 34, n. 2, p. 87-95, 1998.

MATO GROSSO. Secretaria de Desenvolvimento Rural e Agricultura Familiar. Instituto de Defesa Agropecuária do Estado de Mato Grosso. Coordenadoria de Controle das Doenças dos Animais. Sistema Informatizado de Animais. Situação 2010. Cuiabá: INDEA/ MT, 2011b.

MATO GROSSO. Secretaria de Desenvolvimento Rural e Agricultura Familiar. Instituto de Defesa Agropecuária do Estado de Mato Grosso. Coordenadoria de Controle das Doenças dos Animais. Sistema Informatizado de Animais. Situação 2011. Cuiabá: INDEA/ MT, 2011d.

MATO GROSSO. Secretaria de Desenvolvimento Rural e Agricultura Familiar. Instituto de Defesa Agropecuária do Estado de Mato Grosso. Coordenadoria de Controle das Doenças dos Animais. Informe Mensal Sobre Tuberculose: Diagnóstico e Profilaxia da Tuberculose. Cuiabá: INDEA/ MT, 2011c.

MATO GROSSO. Secretaria de Estado de Planejamento e Coordenação Geral. Secretaria Adjunta de Planejamento. Superintendência de Informações. Anuário Estatístico de Mato Grosso - 2009. Cuiabá : SEPLAN-MT/ Tecnomidia Gráfica e Editora Ltda., 2010. 596 p.

MATO GROSSO. Secretaria Estadual de Meio Ambiente. Superintendência de Biodiversidade. Coordenadoria de Ecossistemas. Mapa dos Biomas do Estado de Mato Grosso. Cuiabá, 2009. Disponível em: <http://www.sema.mt.gov .br/index.php?option=com_content\&view=article\&id=170:mapa-dos-biomas-mato- 
grossenses \&catid=38:biodiversidade\&ltemid $=107>$. Acesso em 25 de agosto de 2011a.

MOTA, P.M.P.C., LOBATO, F.C.F., ASSIS, R.A., LAGE, A.P., PARREIRAS, P.M., LEITE, R.C. Ocorrência de tuberculose em rebanhos bubalinos (Bubalus bubalis var. bubalis-Linneus, 1758) no Município de Parintins, Amazonas. Arquivo Brasileiro de Medicina Veterinária e Zootecnia, Belo Horizonte, v. 54, n. 4, 2002

MUNYEME, M.; MUMA, J. B.; SAMUI, K. L.; SKJERVE, E.; NAMBOTA, A. M.; PHIRI, I. G. K.; RIGOUTS, L.; TRYLAND, M. Prevalence of bovine tuberculosis and animal level risk factors for indigenous cattle under different grazing strategies in the livestock/wildlife interface areas of Zambia. Tropical Animal Health and Production, [S.I.], v. 41, p. 345-352, 2009.

NEGREIROS, R. L.; DIAS, R. A.; FERREIRA, F.; FERREIRA NETO, J. S.; GONÇALVES, V. S. P.; SILVA, M. C. P; FIGUEIREDO, V. C. F; LÔBO, J. R.; FREIRAS, J.; AMAKU, M. Situação epidemiológica da tuberculose bovina no Estado de Mato Grosso. Arquivo Brasileiro de Medicina Veterinária e Zootecnia, Belo Horizonte, v. 61, 141 p, 2009. Supplementum 1.

OLIVEIRA, V. M.; FONSECA, A. H.; PEREIRA, M. J. S.; CARNEIRO, A. V. JESUS, V. L. T.; ALVES P. A. M. Análise retrospectiva dos fatores associados à distribuição da tuberculose bovina no Estado do Rio de Janeiro. Arquivo Brasileiro de Medicina Veterinária e Zootecnia, Belo Horizonte, v. 60, n. 3, p. 574579, 2008.

PEREZ, A. M.; WARD, M. P.; TORRES, P.; RITACCO, V. Use of spatial and monitoring data to identify clustering of bovine tuberculosis in Argentina. Preventive Veterinary Medicine, [S.I.], v. 56, p. 63-74, 2002. 
PIAIA, I. I. Geografia de Mato Grosso. 3. ed. Cuiabá: Editora da Universidade de Cuiabá - EDUNIC, 2003. 184 P.

PORPHYRE, T.; STEVENSON, M. A.; MCKENZIE, J. Risk factors for bovine tuberculosis in New Zealand cattle farms and their relationship with possum control strategies. Preventive Veterinary Medicine, [S.I.], v. 86, p. 93-106, 2008.

PROAÑO-PEREZ, F.; RIGOUTS, L.; BRANDT, J.; DORNY, P.; RON, JORGE; CHAVEZ, M. A.; RODRIGUEZ, R.; FISSETTE, K.; VAN AERDE, A.; PORTAELS, F.; BENITEZ-ORTIZ W. Preliminary observations on Mycobacterium spp. in dairy cattle in Ecuador. American Journal of Tropical Medicine and Hygiene, [S.I.], v. 75(2), p. 318-323, 2006.

RAMÍREZ-VILLAESCUSA, A. M.; MEDLEY, G. F.; MASON, S.; GREEN, L. E. Risk factors for herd breakdown with bovine tuberculosis in 148 cattle herds in the South West of England. Preventive Veterinary Medicine, [S.I.], v. 95, p. 224-230, 2010.

REGASSA A.; TASSEW, A.; AMENU K.; MEGERSA, B.; ABUNNA, F.; MEKIBIB, B.; MACROTTY, T.; AMENI, G. A cross-sectional study on bovine tuberculosis in Hawassa town and its surroundings, Southern Ethiopia. Tropical Animal Health and Production, [S.I.], v. 42, p. 915-920, 2010.

ROXO, E. Situação atual da tuberculose bovina no Brasil. Programa Nacional de Controle e Erradicação de Brucelose e Tuberculose Animal, PNCE bovine tuberculosis. Secretaria de Defesa Agropecuária. Docum. PNCE bovine tuberculosis DDD2005, São Paulo, p. 1-5. , 2004.

SALAZAR F. H. P. Ocorrência de tuberculose causada por Mycobacterium bovis em bovinos abatidos em frigoríficos no Estado de Mato Grosso, Brasil. 2005. 68 f. (Mestrado em Ciência Animal) - Faculdade de Medicina Veterinária e Zootecnia, Universidade Federal de Mato Grosso do Sul, Campo Grande, 2005. 
SALAZAR, F. H. P. Ocorrência da Tuberculose Causada por Mycobacterium bovis em Bovinos Abatidos no Estado de Mato Grosso, Brasil. Campo Grande, 2005. 65 p. Biblioteca Digital de Teses e Dissertações da Universidade Federal do Mato Grosso do Sul. Disponível em: <http://www.cbc.ufms.br/tedesimplificado /tde_busca/arquivo.php?codArquivo=94>. Acesso em: 25 de agosto de 2011

THRUSFIELD, M. Veterinary epidemiology. 3. ed., Cambridge: Blackwell Science, 2007. $610 \mathrm{p}$.

THRUSFIELD, M. Veterinary epidemiology. 2. ed., Cambridge: Blackwell Science, 1995. $479 \mathrm{p}$.

ZENDEJAS MARTÍNEZ, H.; MILIAN SUAZO, F.; CUADOR GIL, J. Q.; CRUZ BELLO, G.; ANAYA ESCALERA, A. M.; HUITRÓN MÁRQUEZ G.; GARCÍA CASANOVA. L. Spatial epidemiology of bovine tuberculosis in Mexico. Veterinaria Italiana, [S.I.], v. 43 (3), p. 629-634, 2007.

ZENDEJAS-MARTÍNEZ, H.; TOWNSEND, A. P.; MILIÁN-SUAZO, F. Coarse-scale spatial and ecological analysis of tuberculosis in cattle: an investigation in Jalisco, Mexico. Geospatial Health, [S.I.], v. 3(1), p. 29-38, 2008. 


\section{APENDICE A - Questionário epidemiológico}

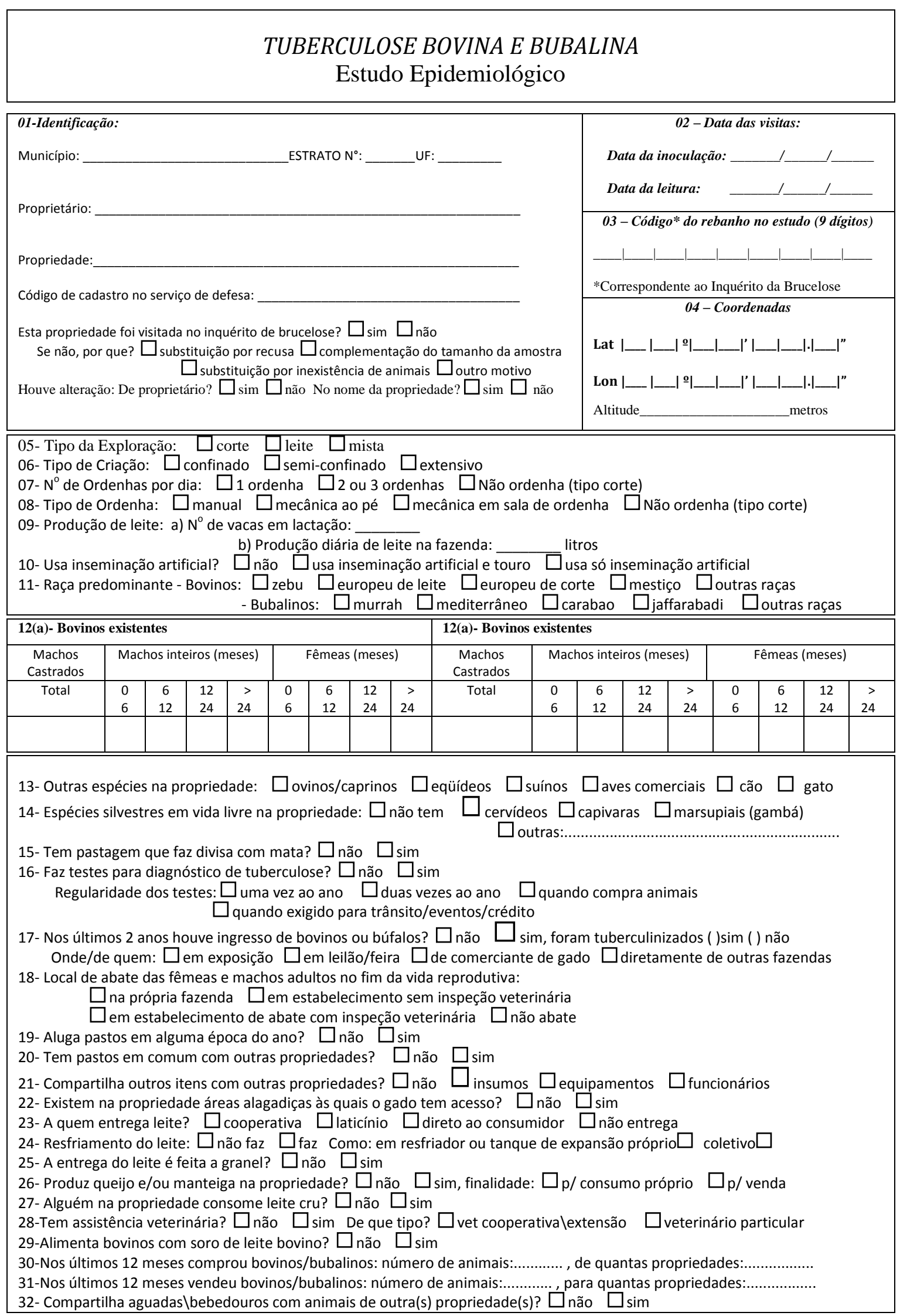

